\title{
ROBERT BOYLE NO CONTEXTO DA TRANSIÇÃO PARA A CIÊNCIA MODERNA: ELEMENTOS PARA UMA ANÁLISE SÓCIO-HISTÓRICA
}

\author{
Bárbara Carine Pinheiro da Anunciação ${ }^{1}$ \\ Hélio da Silva Messeder Neto ${ }^{2}$ \\ Edilson Fortuna de Moradillo $0^{3}$
}

RESUMO: O trabalho em questão tem como objetivo apresentar, a partir de uma perspectiva histórica externalista, as contribuições do químico irlandês Robert Boyle para a ciência Química, fundamentalmente no cenário seiscentista. Para tal, defendemos o uso de uma abordagem sócio-histórica da Ciência, informada pelos seus determinantes sociais e filosóficos mais amplos. Desta forma, apresentamos o cenário político, econômico e epistemológico da transição do mundo feudal para o capitalismo, bem como destacamos a importância das teorias do conhecimento de Bacon e Descartes para o século XVII e como que estas, juntamente com a perspectiva religiosa protestante, contribuíram para a construção do pensamento químico empírico de Boyle.

PALAVRAS-CHAVE: Ciência Moderna; Robert Boyle; Experimentação; Análise Sócio-Histórica.

ABSTRACT: This paper aims to present, from an externalist 
ROBERT BOYLE NO CONTEXTO DA TRANSIÇÃO PARA A CIÊNCIA MODERNA: ELEMENTOS ...

perspective, the contributions of the Irish scientist Robert Boyle for the science of Chemistry in the seventeenth century. This is done according to the socio-historical approach of science, searching for the social, political and economical aspects of the transition from the feudal to the capitalist society as well as for the theories of knowledge by Bacon and Descartes, trying to understand how these factors, along with the Protestant religious perspective, contributed for the construction of the chemical thinking of the empiricist Boyle.

KEYWORDS: Modern Science; Robert Boyle; Experimentation; Socio-Historical Approach. 


\section{UMA CONCEPÇÃO DE HOMEM, DE MUNDO E DE HISTÓRIA: USAR OTELESCÓPIO É FUNDAMENTAL ${ }^{5}$}

A ação do homem não é, apenas, biologicamente determinada. O Homem se torna Homem a partir da incorporação dos conhecimentos produzidos e transmitidos de geração para geração por meio da cultura. A transmissão do legado construído pela humanidade para as novas gerações permite que as gerações anteriores não tenham que a cada momento reinventar a roda. Podemos dizer, portanto, que ao falarmos de ser humano estamos nos referindo a um ser histórico-cultural.

O modo como esse ser pensa tem base nas determinações históricas sob as quais o indivíduo é posto. Portanto, cabe afirmar que as ideias refletem (não de uma maneira mecânica) o mundo que o homem vive e as condições matérias disponíveis de um dado momento histórico. Nas palavras de Marx e Engels (1980, p.25-26):

A produção de ideias, derepresentações e da consciência está em primeiro lugar direta e intimamente ligada à atividade material e ao comércio material dos homens; é a linguagem da vida real (...) Não é a consciência que determina a vida, mas sim a vida que determina a consciência.

Desse modo, entendemos que ao falarmos ou localizarmos um dado cientista, fenômeno ou ideia não podemos desconectálos das influências mais gerais e dos determinantes econômicos, políticos, éticos e epistemológicos que se fizeram presentes na época.

Olhamos para o passado, e portanto para a história, usando o que alguns autores vêm chamando de abordagem externalista. A 
ROBERT BOYLE NO CONTEXTO DA TRANSIÇÃO PARA A CIÊNCIA MODERNA: ELEMENTOS ...

perspectiva externalista pretende apontar a importância do meio social para as mudanças que ocorrem na ciência, acreditando que a história é mais do que um simples contexto de produção de ideias, mas é parte constituinte de qualquer ideia científica ou filosófica, sem reduzir a obra de um pensador somente a um produto de condições sociais de uma época.

Defendemos que uma abordagem como essa pode contribuir para que o indivíduo que se apropria da história não perca de vista uma noção de totalidade, de modo que a história faça sentido e não seja um aglomerado de fatos sem conexão alguma. Trata-se, portanto, de defender na história o uso do telescópio e não apenas do microscópio, como nos ensina Hobsbaw (1991).

A partir das linhas gerais traçadas, vamos nos debruçar nesse texto sobre Robert Boyle, um homem que viveu, pensou e produziu em uma época de transição para o que chamamos de ciência moderna. Diante da vastidão e complexidade da obra boyleana, tentaremos esclarecer a concepção experimental presente na sua obra, tentando tecer uma costura que traga elementos mais gerais do momento social vivido por esse cientista.

\section{DO MUNDO FEUDAL AO MUNDO DO CAPITAL: $O$ PROCESSO DE ENDEUSAMENTO DA MERCADORIA}

A transição da Idade Média para a Modernidade é marcada fundamentalmente pelas transformações na base produtiva, com implicações no modo de produzir conhecimento e valores sociais.

O sistema feudal sucumbiu dando vez ao capitalismo. A terra deixou de ser símbolo de poder ao passo que a mercadoria e seu 
equivalente universal - o dinheiro - ganharam vez e voz na nova era.

Em um período de transição é difícil estabelecer os limites entre o velho e o novo; de modo que em momentos de mudanças de regimes sociais o velho e o novo se encontram frequentemente. Era corriqueiro em um mesmo território coexistirem características do novo e do antigo regime.

A passagem do feudalismo para o capitalismo foi longa, indo do século XV até o início do século XIX. Podemos tomar a segunda metade do século XVIII como o momento no qual a burguesia consolida a sua revolução política e técnica. Neste momento se estrutura o Estado burguês e tem inicio a revolução industrial (NETO e BRAZ, 2009).

Não podemos falar de verdadeira passagem ao capitalismo senão quando regiões suficientemente extensas vivem sob um regime social completamente novo. A passagem somente é decisiva quando as revoluções políticas sancionam juridicamente as mudanças de estrutura, e quando as novas classes dominam o Estado. Por isso a evolução dura vários séculos. (VILAR, 1975, p. 35-36).

A sociedade feudal era estratificada, de modo que havia quase uma impossibilidade de mobilidade social. Os servos pagavam diversos tributos aos seus senhores de forma que o que eles produziam era aquém do que deviam e estas dívidas passavam de pai para filho. Assim, se seu pai fosse servo dificilmente lhe seriam dadas condições sociais de assumir um papel diferente na sociedade.

No século XV, dois acontecimentos marcaram o crescimento comercial europeu. Naquele contexto ocorria a expansão 
ROBERT BOYLE NO CONTEXTO DA TRANSIÇÃO PARA A CIÊNCIA MODERNA: ELEMENTOS ...

marítima, que possibilitou o domínio de novas terras e a aquisição de novos materiais para a venda no continente europeu, gerando um considerável acúmulo de dinheiro pelos burgueses, que posteriormente se tornariam os principais financiadores dos Estados absolutistas, uma vez que emprestavam dinheiro aos reis. Um outro acontecimento considerável foi o segundo cisma que ocorreu na história da Igreja Católica, que levou à criação de uma nova Igreja, a Protestante.

As igrejas protestantes se opuseram a várias posições da Igreja Católica, e dentre as várias oposições destacamos duas significativas, que são a legitimação do empréstimo a juros e a ideia de negar o ócio da classe dominante. Esta postura influenciaria tanto a classe em ascensão, que buscará o crescimento contínuo do fazer negócio, quanto a Ciência em construção que precisava negar a natureza ${ }^{6}$ encantada, endeusada, antropomorfizada.

Neste cenário de diversas e significativas transformações, situava-se a classe burguesa que começava a se estabelecer como classe revolucionária, que com a aquisição e venda de materiais obtinha lucros, o que não a satisfazia, entretanto, pois ela buscava dominar as bases produtivas uma vez que nelas residia a fonte de toda riqueza no novo sistema.

Inicialmente, no sistema doméstico, havia nos burgos os artesãos que compravam as matérias primas, produziam suas mercadorias e as vendiam nas cidades, dominando por inteiro todo o processo produtivo. Com o passar do tempo percebeuse que numa mesma unidade de tempo era possível produzir muito mais mercadorias adquirindo um maior lucro: foi quando o burguês compreendeu que a divisão técnica do trabalho ao extremo tornaria o processo produtivo mais rápido. Agora, no sistema manufatureiro, cada trabalhador era responsável por uma 
etapa da produção das mercadorias, o que gerou uma separação entre criador e criatura, de forma que os trabalhadores não mais se viam no resultado do seu trabalho ${ }^{7}$. Mais adiante, com a revolução industrial ocorrida no século XVIII houve a inserção de maquinário no processo produtivo, fazendo com que o tempo de produção fosse ainda menor e o lucro do burguês, caracterizado por aquilo que Marx vai denominar como mais valor (MARX, 1980), fosse consideravelmente maior.

Desta forma, com a mudança da base produtiva, houve a consolidação do novo regime social. A modernidade se encontrava com as suas bases econômicas bem estabelecidas, associadas à nova base técnica. Com o novo modo de produzir bens materiais consolidado, houve uma mudança no modo de produzir relações sociais, o homem moderno era outro, com outras formas de se relacionar com seus semelhantes e com a natureza. E o modo de produzir conhecimento, claro, também havia mudado.

\section{PARA UMA NOVA FORMA DE PRODUZIR UM NOVO MODO DE PENSAR...}

Neste mundo em transição, a burguesia, de forma revolucionária, vai negar o modo de vida feudal nas três dimensões filosóficas que estruturam a práxis humana: o modo de produzir bens materiais (as questões da economia-política são determinantes); o modo de produzir valores (as questões da ética e da política são determinantes) e o modo de produzir conhecimento (as questões ontológicas e epistemológicas são determinantes).

Neste sentido, no período da transição, podemos afirmar com relação ao conhecimento que: 
ROBERT BOYLE NO CONTEXTO DA TRANSIÇÃO PARA A CIÊNCIA MODERNA: ELEMENTOS ...

Numa fase inicial do período de transição, a rejeição das ideias, da imagem do universo e das maneiras de pensar feudais gerou um certo vazio intelectual, uma vez que não foi imediatamente seguida pelo surgimento de uma nova imagem de universo, deixando sem respostas muitos do problemas levantados. (ANDERY et al, 2012, p. 175).

O homem do período de transição era um indivíduo encarregado de estabelecer as novas leis que regeriam o mundo, uma tarefa nada trivial.

De uma forma geral, até o período medieval o homem buscava conhecer a essência das coisas, o conhecimento era desenvolvido em bases ontológicas: a questão ontológica precede a questão epistemológica. Desde a antiguidade o ser humano buscou desenvolver uma imagem de natureza para o que existia.

A partir do renascimento cultural, que durou do século XIII (o grande século) até o século XVI, os clássicos gregos foram retomados nas universidades europeias, que apesar de ser fundamentalmente religiosas, tinham um espírito laico.

Durante a Idade Média a instrução da população ficou sob a responsabilidade da Igreja Católica, que se preocupou fundamentalmente com a catequização das massas; desta forma, só aqueles que ingressavam numa ordem religiosa tinham o direito de aprender mais que a maioria, mas mesmo assim só poderiam estudar os livros que não eram proibidos pela Igreja, aqueles não listados no Index.

Durante a Idade Média, principalmente na cultura ocidental, predominou uma visão de mundo onde a verdade era Deus ${ }^{8}$ e tudo que Ele revelara na Bíblia. Aos homens só restava contemplar a criação divina sem conhecer suas causas primeiras, que eram ocultas aos mortais. A natureza era endeusada e tratada como 
um grande organismo, o qual deveríamos contemplar para tentar conhecer a sua essência. Poderíamos dizer que a mediação entre conhecimento e sociedade era estabelecida pelo logos de Deus, a teologia.

Fundamentando-se, predominantemente, no sistema cosmológico de Aristóteles (384 a. C. - 322 a. C.) e na astronomia de Ptolomeu (90 - 168), a Igreja, durante a Baixa Idade Média, estabeleceu que o universo era finito, estático e geocêntrico. Durante o período de transição, esta e tantas outras afirmações da Igreja foram negadas, embora não de forma contundente e mássica, pois a Igreja reprimia duramente aqueles que a contrariassem.

É no quadro da Contrarreforma, como renovação do catolicismo para o combate ao protestantismo, que a inquisição toma novo impulso e se, durante a idade média, os alvos privilegiados do inquisidor eram as feiticeiras e os magos, além das heterodoxias tidas como heresias, agora o alvo privilegiado do Santo Ofício serão os sábios: Giordano Bruno é queimado como herege, Galileu é interrogado e censurado pelo Santo Oficio, as obras dos filósofos e cientistas católicos do século XVII passam primeiro pelo Santo Oficio antes de receberem o direito à publicação e as obras dos pensadores protestantes são sumariamente colocadas na lista das obras de leitura proibida (O Index) (CHAUÍ, 2002, p. 68).

Mesmo em um mundo onde não havia espaço para contestações, estas só cresciam tendendo a derrubar esta estrutura cosmológica finita, geocêntrica e orgânica. A Ciência Moderna começará a estabelecer as suas bases sobre um mundo infinito, heliocêntrico e mecânico. 
ROBERT BOYLE NO CONTEXTO DA TRANSIÇÃO PARA A CIÊNCIA MODERNA: ELEMENTOS ...

A Ciência Moderna, que vai instaurar as suas bases filosóficas durante os séculos XVI, XVII, XVIII e XIX, ainda era insipiente e buscava delinear os seus objetos de estudos e os percursos a serem percorridos. Entretanto, uma coisa foi ficando clara: só deveria ser estudado aquilo que fosse possível conhecer. $\mathrm{O}$ conhecimento passou a ser a chave mestra para a nova era. Questões metafísicas não eram bem vindas; a ontologia vai dando lugar a epistemologia; a contemplação perdeu a sua centralidade para a experimentação controlada; a matematização ganhou vez na nova Ciência, ou melhor, nas novas ciências. A Ciência e a Filosofia se separam e a primeira se fragmentou, com a nova base produtiva. Essa nova forma de conhecer, matematizável e relacional, vai deslocar a centralidade de Deus para os indivíduos, isto é, o problema de Deus cabe a cada um, o Estado e a sociedade são laicos. Diríamos: a mediação entre sociedade e conhecimento vai passar a ser dada pelo logos do fazer, da tecnologia.

É neste cenário epistemológico que o novo homem moderno, em formação, vai sendo moldado com relação à concepção de Ciência. Podemos dizer que foram duas as principais vertentes de respostas para direcionar as questões supracitadas inicialmente; uma de base empírica, que teve a sua fundamentação teórica em Francis Bacon (1561 - 1626) e outra de base racional que se pautou nos pressupostos filosóficos de René Descartes (1596-1650)9.

Francis Bacon nasceu na Inglaterra e viveu em um período em que foi consolidada na Inglaterra a transição do catolicismo para o protestantismo. Neste período a Inglaterra cresceu muito do ponto de vista industrial possuindo uma grande força política na Europa.

Bacon, apesar de ter sido um jurista e de ter ocupado grande parte do seu tempo com a vida pública, buscou refletir acerca do 
conhecimento e de como melhor usá-lo para melhorar a sociedade. Para ele a Ciência deveria ser aplicada à indústria, buscando um progresso social, por isso afirmará que saber é poder (ANDERY et al, 2012; BACON, 2007).

Como um bom anglicano, Bacon apontava para o caminho do trabalho da natureza para a glorificação de Deus e para o bem estar do homem. Bacon tinha uma compreensão de um trabalho com a natureza que negava os aspectos centrais da tradição aristotélica. Para tal, ele propôs o Novum Organum como forma de apresentar um novo domínio sobre a natureza, inaugurando um novo tipo de empirismo.

O Novum Organum fez uma proposta de reformulação da concepção predominante de Ciência, que era contemplativa. Isso não significa que a ciência não realizasse observações empíricas nem deixasse de fazer experimentos, porém, de fato, a observação e a experimentação efetuadas, por exemplo, por Galeno e Hipócrates, não tinham como objetivo a transformação da natureza, e sim ajudá-la com a arte a realizar o que ela sozinha não teria forças para fazêlo (ZARTEKA, 2004, p. 101).

Para Bacon a natureza e o homem te tornaram corruptíveis a partir do pecado original. Antes da desobediência primeira, homem e natureza eram perfeitos e o homem tinha domínio irrestrito sobre ela. Segundo o filosofo experimental seiscentista, era necessário resgatar este domínio por meio de um conhecimento puro e verdadeiro (ZATERKA, 2004).

O filósofo inglês afirma que o melhor meio para se alcançar o conhecimento verdadeiro é a experimentação controlada. Para isto é necessário que os homens se desprendam de toda a sua 
ROBERT BOYLE NO CONTEXTO DA TRANSIÇÃO PARA A CIÊNCIA MODERNA: ELEMENTOS ...

sensibilidade que ocasionará interpretações equivocadas dos fenômenos. A esta subjetividade humana que interfere na pureza das interpretações dos resultados experimentais Bacon deu o nome de Ídolos.

Segundo Bacon, existem quatro tipos de ídolos: os ídolos da caverna, os ídolos da tribo, os ídolos do foro e os ídolos do teatro.

São quatro as classes os Idola que bloqueiam a mente humana. Para melhor apresenta-los, lhes assinamos nomes, a saber: Ídolos da Tribo, Ídolos da Caverna, Ídolos do Foro e Ídolos do Teatro (BACON, 1979, p.358).

Os Ídolos da caverna são singulares e são construídos a partir da educação recebida, pela convivência familiar, ou com quaisquer pessoas. Já os ídolos da tribo tem raízes na coletividade dos próprios homens, eles são oriundos da herança cultural que é passada de geração para geração. Os ídolos do foro são característicos do domínio da verdade pelo discurso, a arte da oratória quando utilizada de forma inadequada pode bloquear o intelecto. Por fim, os ídolos do teatro são absorvidos socialmente pelos indivíduos através da convivência com doutrinas religiosas ou filosóficas que acabam por bloquear a visão do homem para certos fenômenos (OLIVEIRA, 2000).

Assim, para Bacon, o conhecimento verdadeiro deve ser purificado dos seus vícios (os ídolos). Por isso, o seu novo empirismo nascente não despreza a especulação racional, mas se opõe a todo conhecimento que se dá pela especulação, nega as ideias predeterminadas da natureza. Propõe o trabalho direto com as coisas para romper com as ideias de base metafísica preconcebidas, principalmente a aristotélica, foco de seus 
questionamentos. E, neste trabalho direto, não se deve saltar das sensações das coisas particulares para os axiomas mais gerais, ao contrário, deve-se caminhar por etapas, para alcançar gradualmente as formulações gerais (BACON, 1979).

Com este método, o filósofo empirista estabelece as bases filosóficas para o método indutivista moderno, que tinha como premissa partir de resultados experimentais singulares até chegar a generalizações científicas, por meio da produção de leis e teorias.

O método baconiano para investigação da natureza é bastante diferente do método desenvolvido por René Descartes, apesar de ambos se preocuparem com a minimização dos erros. Para Bacon é necessário expurgar os ídolos para se alcançar um conhecimento científico e verdadeiro. Já para Descartes o caminho está na razão.

René Descartes nasceu em La Haye, na França. Foi educado por um colégio jesuíta e ingressou na vida militar em 1618 servindo sob o comando de Mauricio de Nassau.

Descartes, para chegar às bases mais sólidas de sua filosofia, percorre um caminho que perpassa pela dúvida cética, pela dúvida metodológica e pela proposição de um universo criado a partir de caracteres matemáticos.

O filósofo francês inicia a sua inquietação filosófica questionando a solidez dos conhecimentos adquiridos por ele ao longo da vida.

Há já algum tempo eu me apercebi de que desde meus primeiros anos, recebera muitas falsas opiniões como verdadeiras, e de que aquilo que depois eu fundei em princípios tão mal assegurados não podia ser senão mui duvidoso e incerto (DESCARTES, 2004, p. 83). 
ROBERT BOYLE NO CONTEXTO DA TRANSIÇÃO PARA A CIÊNCIA MODERNA: ELEMENTOS ...

E afirma: "Aplicar-me-ei seriamente e com liberdade em destruir em geral todas as minhas antigas opiniões" (DESCARTES, 2004, p. 83-84).

Descartes passa por um primeiro momento cético, ainda em suas meditações nos períodos em que ele ainda servia as forças armadas. Ele se pergunta se não seria Deus um ser engendroso que brinca com todos os seres humanos que na verdade viveriam em um sonho e não em uma realidade. Neste momento o filósofo francês vive um momento de grande ceticismo.

Suporei, pois, que há não um verdadeiro Deus, que é soberana fonte da verdade, mas certo gênio maligno, não menos ardiloso eenganador do que poderoso, que empregou toda a sua indústria em enganar-me (DESCARTES, 2004, p. 84).

Para Descartes, os sentidos são enganosos e não nos levam a conhecimentos verdadeiros e científicos. A experiência, para ele, possui características subjetivas em suas bases, decorrentes da sensibilidade dos sujeitos.

Tudo o que recebi, até presentemente, como o mais verdadeiro e seguro, aprendi-o dos sentidos ou pelos sentidos, ora, experimentei algumas vezes que esses sentidos eram enganosos (DESCARTES, 2004, p.84).

Vale destacar que apesar de suas viagens o contato de Descartes com o protestantismo foi mínimo, de modo que esta religião não interferiu no seu modo de conceber a natureza. Deste modo, Descartes ao resolver o seu problema da dúvida 
cética com o "penso logo existo" postula que todos podem chegar ao conhecimento verdadeiro pela via da razão, pois Deus, que é um ser bondoso, dotou a todos de razão. Desta forma, Descarte soluciona a sua dúvida metódica propondo um método científico de base racional.

Como etapas desse caminho reto, Descartes propõe quatro regras do método, que de tão simples podem ser seguidas e adotadas por qualquer pessoa que tenha a firme convicção de avançar nas vias do conhecimento verdadeiro (DESCARTES, 2008, p. 21).

1. Não aceitar nada como verdadeiro, sem antes passar pelo crivo da razão.

2. Tudo o que aparece como complexo deve ser dividido em tantas partes simples quanto possíveis.

3. Estabelecer uma ordem lógica necessária entre estes elementos simples, e não uma mera sucessão temporal.

4. Revisar os passos anteriores, a fim de se ter certeza de que nada foi esquecido.

A filosofia moderna, até a proposta de conciliação feita por Kant (1724 - 1804), oscilou muito entre a vertente empirista e a racionalista. A seguir elucidaremos como a proposição metodológica empirista impulsionou a ciência moderna no século XVII, destacando um cientista extremamente peculiar na química: Robert Boyle (1627 - 1691). Apesar da perspectiva racionalista ter tensionado fortemente o empirismo e ter sido muito significativa para a nova filosofia natural, ela não foi a tônica do trabalho boyleano. 
ROBERT BOYLE NO CONTEXTO DA TRANSIÇÃO PARA A CIÊNCIA MODERNA: ELEMENTOS ...

\section{BOYLE E A EXPERIMENTAÇÃO NO SÉCULO XVII: UM CAMINHO SEGURO PARA SE CHEGAR À VERDADE}

No século XVII nascia na Europa o químico irlandês Robert Boyle, que era oriundo de família nobre, filho mais velho de um dos homens mais ricos e influentes da Grã-Bretanha. Boyle teve sua formação acadêmica inicialmente em casa, posteriormente no Eton College e complementou os seus estudos por viagens a França, Itália e Suíça. Ainda durante a sua formação inicial ele se converteu religiosamente ao protestantismo, passando a ser um escritor no campo da moral, da filosofia e da religião. E em meados do século desloca a sua preocupação para a Química e constrói um laboratório em sua casa, tornando-se um entusiasta da prática experimental; fato que não o distancia de sua prática religiosa.

Apesar de muitos dos pensadores que estabeleceram as bases da ciência moderna serem oriundos de universidades católicas e muitos deles defenderem esta religião, de modo que pregavam a separação entre questões de fé e questões científicas, a religião protestante foi muito importante para a solidificação de certos princípios gerais para a Ciência seiscentista, como a base experimental e o utilitarismo.

Robert Boyle era um cristão virtuoso e se aproximou da ciência química como meio de glorificar ao Senhor. Naquele cenário, ele buscou se aproximar da filosofia natural como meio de desenvolver o seu projeto religioso e para ele a ciência que mais se aproximava dos desígnios de Deus era a Química. Boyle procurou incorporar a Química ao contexto da nova filosofia natural e derrubar a visão desta como uma ciência oculta e mística como ela era vista no período em razão das antigas práticas alquímicas. 
Cultivei a química [...] não para multiplicar processos ou ganhar reputação com eles, mas para servir para a fundação de uma história da natureza experimental e outras matérias úteis, na qual uma sólida teoria pode ser construída no decorrer do tempo (BOAS HALL, 1958, p. 277).

No século XVII, difundiam-se na Europa as concepções químicas da Iatroquímica, que foi um período em que a ciência química possuiu grandes entrelaçamentos com a medicina, através da formação, universitária ou não, dos médicos químicos. Os grandes representantes desta vertente eram Paracelso e Van Helmont que negavam a iatroquímica tradicional galênica ensinada nas universidades. Eles defendiam a produção experimental de medicamentos químicos; a correlação espiritual entre microcosmo e macrocosmo; e viam a prática experimental como um equivalente da experiência espiritual. Na concepção dos iatroquímicos seguindo o caminho da experiência científica poderíamos atingir uma compreensão da vida espiritual. Estas concepções iatroquímicas foram inicialmente muito importantes para as proposições filosóficas de Boyle.

A química oferecia uma ilustração ideal das potencialidades deste método. Os produtos naturais foram ordenados por Deus para o uso do homem, mas suas propriedades não poderiam ser reveladas diretamente, uma vez que a transgressão de Adão sacrificou nossos direitos a uma experiência direta sobre a pureza da natureza (WEBSTER, 1974, p. 285).

O cientista inglês tinha um interesse pela filosofia natural com um objetivo mais amplo, que era conhecer Deus através de suas obras. Sendo um filósofo natural cristão de base puritana, 
ROBERT BOYLE NO CONTEXTO DA TRANSIÇÃO PARA A CIÊNCIA MODERNA: ELEMENTOS ...

ele construiu seu empreendimento epistemológico levando em consideração o plano divino da criação e o bem estar do próximo (ZATERKA, 2004).

Merton define puritanismo de uma forma bastante abrangente: "Anglicanos, calvinistas, presbiterianos, independentes, anabatistas, quakers e milenaristas" (MERTON In ZATERKA, 2004).

Para ele, Merton, há uma forte relação entre o puritanismo e a ciência inglesa seiscentista, pois o puritanismo tinha como um dos seus objetivos, para dar razão a existência das pessoas, a glorificação de Deus. Assim, uma forma de glorificar a Deus é demonstrar a sua presença nas obras humanas, que se dá através do trabalho útil. Utilidade e verdade se articulam e passam a assumir uma mesma identidade. Desta forma, a nova concepção de ciência que está aparecendo em Boyle tem essa trípice relação: "estar a serviço do indivíduo, da sociedade e de Deus" (ZATERKA, 2004, p. 34).

Essa ciência empírica e utilitária, que tem nos sentidos a sua base determinante, vai apelar para uma forma de experimentar diferente, que tem em Bacon uma referência importante. Essa nova forma de conhecer, que nega o ócio e ajuda as pessoas nas suas atividades diárias, põe em movimento a ação dos homens sobre a natureza.

Em outras palavras, preferiam-se a manipulação ativa à contemplação passiva, frutos práticos em lugar de ficções estéreis. Sendo assim, o autor pôde concluir sua tese: se de fato a nova filosofia natural estava voltada parta fins utilitários, os homens de ciência se voltaram principalmente para os problemas que mais afligiam os homens da época - a navegação, a drenagem e ventilação 
das minas, a utilização de minérios, etc. Em resumo, explica Merton, houve um crescente interesse pela ciência em meados do século XVII na Inglaterra, pois um dos fatores religiosos predominantes - o ethos puritano - favoreceu esse interesse. Com os homens de ciência voltados aos problemas efetivamente práticos, houve um aumento claro na expansão do mercado, e com isso a nova forma da economia, o capitalismo, estava implantada (ZATERKA, 2004, p. 34).

Aqui é importante perceber o quanto essa nova forma de conhecer está em consonância com a nova sociedade que está se estruturando e que tem na mercadoria o elemento nucleador da nova forma de produzir bens materiais.

Os Brilhantes sucessos das ciências naturais durante os séculos XVI e XVII foram condicionados pela desintegração da economia feudal, pelo desenvolvimento do capital mercantil, das relações marítimas internacionais e da indústria pesada (mineração) (HESSEN, 1971).

Sobre a ação de Deus sobre os homens e a natureza podemos dizer que, para Boyle, as regularidades existentes no mundo são expressão da vontade manifesta de um ente superior que dá curso a natureza - são as necessidades naturais, ou melhor, os costumes de Deus. Contudo, esse ser divino pode suspender essa ordem natural - as leis da natureza, os seus costumes - levando àquilo que denominamos de milagres, denominados por Ele de experimentos divinos, milagres estes que estão fora do alcance racional do homem. Assim, no empreendimento epistemológico de Boyle, vamos encontrar as verdades que de fato podem ser dominadas pela razão e aquelas que estão acima da razão 
ROBERT BOYLE NO CONTEXTO DA TRANSIÇ̃̃O PARA A CIÊNCIA MODERNA: ELEMENTOS ...

(ZATERKA, 2004). Por isso, o limite do conhecer em Boyle está ligado a essa nova Ciência da natureza, que tem como um dos pilares a perspectiva empirista de cunho baconiana ${ }^{10}$.

O autor de Químico Cético havia sido membro da Royal Society e era um seguidor fiel do empirismo baconiano. Desta forma ele acreditava que a experiência deveria ter um lugar privilegiado e fundante em qualquer empreendimento epistemológico. Ele discordava de qualquer prática científica que utilizasse experimentos de difícil reprodutibilidade e que não desse à prática empírica um lugar de destaque no processo de formulação de ideias.

O químico irlandês julga a matemática como uma importante ferramenta para a ciência, entretanto a aceita somente como um instrumento complementar ou auxiliar ao método experimental. Para ele a matemática sozinha não pode fornecer as razões que regem a ação dos corpos (ZATERKA, 2004). Boyle utiliza a razão e a matemática como elementos necessários para a filosofia natural, mas elementos que devem ser utilizados a posteriori.

Boyle na esteira de Bacon, acredita que a boa filosofia natural tem que dissecar os fenômenos da natureza. Ora, a melhor ciência para alcançar tal objetivo é a química. Por meio dos experimentos químicos aprendemos não somente sobre os ingredientes materiais dos corpos, mas também sobre a eficácia de ingredientes particulares, por que as circunstâncias dos experimentos são cuidadosamente controladas. Estes procedimentos ficam claros em sua obra o Ensaio do Nitro (ZATERKA, 2004, p. 157).

Através da prática rigorosa de experimentos controlados, Boyle desenvolveu muitos conhecimentos na área química e foi uma figura notável na química seiscentista. 
No período em que o médico químico Van Helmont propõe a teoria ácido-alcalino de base místico-simbólicas, Boyle parte em defesa de uma ciência empírica e aponta para o erro da teoria. Para Helmont, a digestão seria equivalente à fermentação, assim as secreções viscerais poderiam ser classificadas como os produtos finais da fermentação, em ácido e alcalino. De acordo com esta teoria, todos os materiais deveriam conter substâncias ácidas e alcalinas. Helmont tinha a nítida pretensão de unificar a química e a fisiologia. Já para o químico inglês Robert Boyle, havia um erro na generalização do ácido alcalino. Ele o provou realizando uma série de testes químicos e físicos, com a intenção de sistematizar melhor as substâncias ácidas e alcalinas, Boyle identifica uma série de substâncias que não se enquadravam nos comportamentos, por ele estabelecidos, para substâncias ácidas e para as básicas. A estas substâncias o químico inglês deu o nome de neutras.

Com a descoberta das substâncias neutras, o futuro da teoria que classifica as substâncias em ácidas e alcalinas estava comprometido. No entanto, a teoria ácido-alcalina sobreviverá com modificações até o início do século seguinte e, algum tempo depois, o sistema de classificação de Boyle e seus testes para substâncias ácidas, básicas e neutras tornam-se comuns, aceitos como padrão na maioria dos compêndios de química.

Boyle também realizou uma série de experimentos para testar diferentes extratos de plantas, como por exemplo, o paubrasil, que era usado no tingimento de tecido, cuja mudança de cor com o tempo ou na presença de certas substâncias já havia sido notada. Boyle vê a utilidade do extrato de pau-brasil como indicador de substâncias ácidas e daquelas alcalinas. Além do pau brasil ele utilizou o tornassol e o extrato de violetas como 
indicadores em seus experimentos. A partir dos trabalhos de Boyle, o uso de extratos de plantas como indicadores se tornou frequente, vindo a ser uma prática corriqueira na química do século XVIII, principalmente nos processos de titulação.

Acerca dos seus estudos sobre a estrutura da matéria Boyle se revela como um atomista cristão. Embora fosse partidário do atomismo, foi militante na luta contra a disseminação do ateísmo que ameaçava insurgir na Inglaterra naquela época, ateísmo científico oriundo da retomadas das concepções atômicas epicuristas. Entre o estudo de obras de outros pensadores, seu interesse sobre a teoria atômica é especialmente conectado à leitura das obras de Gassendi, elaborando sua própria "teoria corpuscular". Boyle preferiu chamar de teoria corpuscular para fugir do termo atomismo, até então relacionado a questões ateístas.

Sobre os processos reacionais são conhecidas as ideias de Boyle que considerava a afinidade das substâncias reagentes como resultado de formas apropriadas das partículas que lhes permitiam aderir umas às outras (JUSTI, 1998). Com as ideias de Boyle surge uma oposição às noções místico-simbólicas de afinidade como amor e ódio, em direção a uma explicação mecanicista e que admitia um novo modelo de mundo (MAAR, 1999). Ele rejeitou o animismo e interpretações metafísicas e defendeu modelos mecânicos para explicar as causas das reações químicas. As suas afirmações eram baseadas em experimentos realizados de forma qualitativa, procurando estabelecer a composição dos materiais.

\section{CONSIDERAÇÕES FINAIS}

Sem desconhecer o intenso debate sobre a forte influência dos fatores externos na nova concepção de ciência emergente, e 
das várias determinações do real que podem influenciar em um determinado empreendimento epistemológico, inclusive com suas relações lógicas e internas, entendemos que não podemos negar os vínculos estreitos que estão sendo estabelecidos entre as formas de produzir conhecimento, bens materiais e valores na transição do feudalismo para o capitalismo.

Assim, buscamos apontar, por meio de uma perspectiva externalista, as contribuições do cientista do século XVII Robert Boyle para a Ciência Moderna. Em um cenário de grandes mudanças nos campos religioso, ético, político, econômico, científico e cosmológico, encontra-se Boyle influenciado por essas alterações ocorridas nas várias esferas da práxis humana.

Robert Boyle, por vezes, é um cientista pouco lembrado quando se trata da longa revolução da Química. Objetivamos aqui mostrar a relevância do seu trabalho para a Ciência moderna, em especial para a Química.

Apontamos neste trabalho como Boyle tenta superar as concepções místico-simbólicas de Ciência herdadas da alquimia. Para o cientista irlandês, a observação neutra e a experimentação controlada tinham uma papel crucial para a ciência em ascensão. Dentro desta ótica, Boyle foi fortemente influenciado por Francis Bacon que foi um dos pioneiros a estabelecer as bases empíricas para o método científico moderno. Além disso, por meio da experimentação, Boyle, que era um cristão fervoroso, tinha como finalidade glorificar a Deus nas coisas, rompendo com o ócio contemplativo tão estimado na filosofia natural antiga.

Os pressupostos teológicos de Boyle foram fundamentais para que ele pudesse desenvolver uma concepção ontológica de natureza que necessariamente reflete a sua filosofia natural. Para ele, estudar a natureza significa compreender melhor a 
ROBERT BOYLE NO CONTEXTO DA TRANSIÇÃO PARA A CIÊNCIA MODERNA: ELEMENTOS ...

manifestação de Deus nas coisas. Nesta perspectiva, é inviável pensarmos em uma ciência natural que tenha pressupostos a priori, de modo que uma razão humana a priori nunca poderia abarcar todos os efeitos divinos. Para Robert, a observação e a experimentação purificada dos sentidos (expurgada dos ídolos baconianos), são a chave para se construir um conhecimento científico puro e verdadeiro. No método boyleano, a razão e a matemática tem lugar como ferramentas e não posição de destaque metodológico.

Apesar de não ter criado grandes linhas de pesquisa, Boyle desenvolveu várias pesquisas de base experimental que fortaleceram a química nos campos reacional, nos estudos ácidobase, na teoria corpuscular da matéria, dentre outros.

Como evidenciamos, Boyle foi um homem do seu tempo, que foi influenciado pelas transformações sociais ocorridas no período de transição. Um homem que conciliava pressupostos científicos, filosóficos e teológicos a fim de desenvolver uma concepção de mundo que estivesse a favor de Deus e do próximo. Nesta ótica, apontamos Boyle como uma figura extremamente importante no cenário da química seiscentista e afirmamos que ele teve um papel crucial para o desenvolvimento da química como ciência experimental na modernidade.

\section{NOTAS}

${ }^{1}$ Professora do Instituto de Química da Universidade Federal da Bahia (UFBA); doutoranda no Programa de Pós Graduação em Ensino, Filosofia e História das Ciências UFBA-UEFS (barbaracarine@bol.com.br)

${ }^{2}$ Professor no Instituto de Química da Universidade Federal da Bahia (UFBA); 
doutorando no Programa de Pós Graduação em Ensino, Filosofia e História das Ciências UFBA-UEFS (messeder3@yahoo.com.br) ${ }^{3}$ Professor do Instituto de Química da Universidade Federal da Bahia (UFBA) e do Programa de Pós Graduação em Ensino, Filosofia e História das Ciências UFBA-UEFS (edilsonfmoradillo@gmail.com)

${ }^{4}$ As expressões que se referem a indivíduos ou coletivos humanos serão grafadas no masculino sem que isso represente ignorar o discurso de gênero, nem desprezo pelo gênero feminino.

${ }^{5}$ Eric Hobsbawm (1991, p.45) afirma que: "Não há nada de novo em escolher olhar o mundo por um microscópio, ao invés de um telescópio. Na medida em que concordamos que estamos estudando o cosmo, a opção entre o microcosmo e o macrocosmo é uma questão de escolha da técnica adequada. É significativo que um maior número de historiadores atualmente considere o microscópio muito útil, mas isso não significa necessariamente que rejeitem o telescópio como coisa ultrapassada.”.

${ }^{6}$ Alguns autores fazem distinção do termo natureza com " $\mathrm{n}$ " maiúsculo (Natureza), para se referir ao conjunto de entidades materiais e fenômenos realmente existentes no mundo; do de natureza com "n" minúsculo (natureza), no sentido de essência de um ser/ente, a exemplo de Abrantes (1998). Algo similar podemos encontrar em vários filósofos, desde a antiguidade, a exemplo de Aristóteles (PESSANHA, 1983). Neste texto não faremos distinção e usaremos com " $n$ " minúsculo.

${ }^{7} \mathrm{Na}$ verdade esse novo processo de produção vai alienar o trabalhador no sentido subjetivo: ao produzir ele não tem o controle/conhecimento da totalidade do processo, quanto no sentido objetivo: a produção vai ter como finalidade o valor de troca e não o de uso, com um agravante, o objeto não pertence ao trabalhador (MARX, 1980).

${ }^{8}$ Existem várias posições quando se trata da concepção de Deus, por exemplo, no naturalismo realista, que busca entender a constituição do sujeito epistemológico a partir da natureza, podemos listar as seguintes posições segundo Pessoa Jr (2011): “O naturalismo é consistente com pelo menos cinco posições a respeito de Deus: a) ateísmo: Deus não existe; b) agnosticismo: a questão da existência de Deus não pode ser resolvida e por isso suspendemos nosso juízo sobre esta questão; c) panteísmo: Deus se identifica com a Natureza 
e não é nada além disso; d) deísmo: Deus criou a Natureza, com suas leis, mas não interfere no curso da natureza; assim, não ocorrem milagres.

Podemos mencionar também uma visão "naturalista animista" (próxima talvez ao panteísmo), bastante difundida hoje em dia, segundo a qual pode não existir um Deus inteligente a quem devamos adorar, mas existiria uma espécie de "força" ou "energia" que guia a Natureza e dá sentido às nossas vidas. $\mathrm{O}$ termo "nova era" é às vezes associado a esta postura naturalista, que também é simpática à astrologia e a outras pseudociências"

${ }^{9}$ Aqui, é importante esclarecer que o novo debate que aparece nesse período, entre racionalismo e empirismo, é bem mais extenso do que o apresentado nesse trabalho. A nossa intenção principal é discutir a influencia da filosofia baconiana na prática científica boyleana, num cenário de mudanças racionais e empíricas, por isso vamos privilegiar Bacon e Descartes.

Poderíamos citar outros empiristas mais contundentes do período como Thomas Hobbes (1588-1670) e John Locke (1632-1704). Assim como outros racionalistas importantes do período como Benedictus Spinoza (1632-1677) e Gottfried Leibniz (1646-1716).

${ }^{10}$ Aqui, é bom resaltar, que para alguns autores essa distinção entre empirista e racionalista em Boyle não é algo trivial. Marilena Chauí, no prefácio do livro de Zarteka, diz: "Luciana Zarteka nos mostra que Robert Boyle é um racionalista e um empirista. Por que pode fazê-lo? Por que assinala que a cisão tradicional entre "racionalistas" e "empiristas" deixa na sobra o mais importante, isto é, que a distinção entre eles não passa, como se costuma imaginar, pela recusa da experiência, por parte dos primeiros, nem pela recusa do papel da razão, por parte dos segundos, e sim pelo lugar que atribuem a cada uma delas. Para os chamados empiristas, a experiência (por meio dos experimentos controlados) é fundante do conhecimento enquanto a razão, comprovadora e verificadora dos resultados obtidos. Para os chamados racionalistas, a razão é fundante do saber, cabendo à experiência a tarefa da comprovação e da verificação dos resultados" (ZARTEKA, p. 12, 2004). 


\section{REFERÊNCIAS}

ANDERY, M. A et al. Para compreender a ciência: uma perspectiva histórica. Rio de Janeiro: Garamond, 2012.

BACON, F. Novum Organum ou verdadeiras indicações acerca da interpretação da natureza. Nova Atlântida. Tradução e notas J. A. Reis de Andrade. São Paulo: Abril Cultural, 1979 (coleção os Pensadores.

BACON, F. O Progresso do Conhecimento; tradução, apresentação e notas Raul Fiker. São Paulo: Editora UNESP, 2007.

BOAS HALL, M. Robert Boyle and seventeenth-century Chemistry. Cambridge: Cambridge University Press, 1958.

CHAUI, M. Introdução à história da filosofia. São Paulo: Companhia de Letras, 2002, v. 1.

DESCARTES, René. Discurso do Método. Tradução de Paulo Neves. Porto Alegre: L\&PM Pocket,2008.

DESCARTES, René. Meditações sobre Filosofia Primeira. Tradução de tradução de Fausto Castilho. São Paulo: UNICAMP, 2004.

HESSEN, B. “The Social and Economic Roots of Newton's Principia," In N. I. Bukharin, et al. Science at the Crossroads: Papers from the Second International Congress of the History of Science and Technology. Londres: Kniga, 1971. pp. 147-212. Tradução de João Zanetic e Maria Regina D. Kawamura.

HOBSBAWM, Eric. O ressurgimento da narrativa: alguns comentários. Trad. Denise Bottmann. RH - Revista de História, n.2/3, Campinas-SP: Gráfica IFCH/ Unicamp, 1991. 
ROBERT BOYLE NO CONTEXTO DA TRANSIÇÃO PARA A CIÊNCIA MODERNA: ELEMENTOS ...

JUSTI, R. S. A afinidade entre as substâncias pode explicar as reações químicas? Química Nova na Escola. n.7, mai., 1998.

MAAR, H. J.; Pequena História da Química, parte I, Ed. PapaLivro: Florianópolis, 1999.

MARX, K, O capital: o processo de produção do capital. Rio de Janeiro: Civilização Brasileira, Livro 1, v.1. 1980.

MARX, K; ENGELS, F. A ideologia alemã I. Lisboa, Editorial Presença, 1980.

Merton, R. K. Ciência, tecnologia y sociedad em La Inglaterra Del siglo XVII In: ZATERKA, L. A filosofia experimental na Inglaterra do século XVII: Francis Bacon e Robert Boyle. São Paulo: Associação Editorial Humanitas: Fapesp, 2004.

NETO, J. P. e BRAZ, M. Economia Política: uma introdução, 5 edição, São Paulo: Cortez, 2009.

OLIVEIRA, R. A escola e o ensino de Ciências. Porto Alegre: Unisinos. 2000. $1^{\circ}$ ed.

PESSANHA, J. A. M. Coleção os Pensadores: Aristóteles. 2.ed., São Paulo: Abril Cultural, v. 1, 1983.

PESSOA - Jr, O. O Dogmatismo Científico de Tradição Materialista. Texto Impresso não publicado, 2011.

Vilar, P. Marx e a história. In: HOBSBAWM, E. J. (org). História do marxismo. Rio de Janeiro: Paz e Terra, 1980, vol I.

WEBSTER, C. The intelectual revolution of the seventeenth century. London/ Boston: Routledge \& Kegan Paul, 1974.

ZATERKA, L. A filosofia experimental na Inglaterra do século XVII: Francis Bacon e Robert Boyle. São Paulo: Associação Editorial Humanitas: Fapesp, 2004. 